\title{
Vitamin D3 Levels in Idiopathic Low Backache Women of Child Bearing Age attending Neurosurgery OPD
}

\author{
Mahjabeen Memon, Vashdev Khemani, Riaz Ahmed Raja
}

\begin{abstract}
OBJECTIVE: To find the association between low levels of vitamin D3 and Idiopathic Low Back Pain (LBP) among the women of child bearing age attending Neurosurgery OPD, and to find the association between observing veil and vitamin D3 deficiency.

METHODOLOGY: Cross-sectional study, conducted at Neurosurgery OPD, Civil Hospital, Hyderabad, Pakistan from December 2013 to May 2014. Questionnaires from 100 patients selected by Stratified random sampling of only Women of Child Bearing Age (15-49 years) having LBP of unknown cause were included. Vitamin D3 test reports were obtained. Software's used were Microsoft Excel, SPSS version 16.0 and SPSS version 20.0 .

RESULTS: Out of 100 patients, 60 patients $(60 \%)$ were Vitamin D3 deficient $(0-20 \mathrm{ng} / \mathrm{ml}), 23$ patients $(23 \%)$ were having Vitamin D3 insufficiency $(20-30 \mathrm{ng} / \mathrm{ml})$ and those with Vitamin D sufficiency $(30-100 \mathrm{ng} / \mathrm{ml})$ or efficiency $(>100 \mathrm{ng} / \mathrm{ml})$ were only 15 patients $(15 \%)$ and 2 patients $(2 \%)$ respectively. Out of 60 females who were Vitamin $D$ deficient, 49(81.7\%) were observing veil (no adequate sunlight exposure) and 11 (18.3\%) were without veil (well-exposed to sun) which was found to be statistically significant.

CONCLUSION: Vitamin D3 deficiency or insufficiency is an associated risk factor for Idiopathic LBP, also observing veil can lead to significantly low vitamin D3 levels associated with high prevalence of LBP risk in women of child bearing age in otherwise sunny regions. Therefore, adequate vitamin D3 supplementation can be mandatory to prevent and treat LBP. This needs to be evaluated in further researches at a local level.
\end{abstract}

KEY WORDS: Vitamin D3, Idiopathic Low Backache, Child Bearing Age.

This article may be cited as: Memon M, Khemani V, Raja RA. Vitamin D3 Levels in Idiopathic Low Backache Women of Child Bearing Age attending Neurosurgery OPD. J Liaquat Uni Med Health Sci. 2019;18(03):201-5. doi: 10.22442/jlumhs.191830628

\section{INTRODUCTION}

Low back pain is very common and affects many people. It has been found that between $5-10 \%$ cases of acute low back pain end up being chronic. This chronic low back pain (CLBP) is responsible for a high global health burden and disability. The prevalence of CLBP increases linearly from $3^{\text {rd }}$ to $6^{\text {th }}$ decade of life, prevailing more among women ${ }^{1}$.

In $85 \%$ of low back pain (LBP) patients, no obvious cause can be identified (i.e. cause is unknown), and it is labeled as "Idiopathic low back pain." Therefore, lack of apparent cause and consequent diagnosis is responsible for various vague classifications. For the sake of simplicity, LBP is classified into Acute $(<6$ weeks), sub-acute (6-12 weeks) and chronic (>12 weeks). Frequently it is acute, whereby $90 \%$ of cases recover within a month; majority without cure and several without even a hospital visit ${ }^{2}$. Physicians' capability to diagnose a single strong pathologic evidence of the pain is highly limited, making treatment unlikely. Therefore, treatment is only supportive, aiming at relieving pain and improving function ${ }^{3}$. The normal serum level of vitamin D3 ranges from $30-100 \mathrm{ng} / \mathrm{ml}$. Its deficiency means a serum level of less than $20 \mathrm{ng} / \mathrm{ml}$, and its insufficiency as $20-30 \mathrm{ng} / \mathrm{ml}^{4}$.

Vitamin D3 deficiency may be responsible for lower functionality; hence high risk low back pain patients should be screened for hypovitaminosis $\mathrm{D}^{5}$. The dilemma of idiopathic low back pain remains a challenge to health professionals. Therefore, authors mostly recommend early and regular screening for vitamin D3 deficiency as a part of routine health care workup for idiopathic low back pain ${ }^{6}$.

Vitamin D3 deficiency is a major global health problem, even in those people living in sunny countries (like Pakistan) where it was assumed that UV rays were sufficient enough to prevent its deficiency, and in developed countries where vitamin D3 supplementation has been put into practice for years. Nonetheless, most countries lack population representative data, and no sufficient studies have been conducted yet to analyze clear association between vitamin D3 deficiency and low back pain ${ }^{7}$. However, it has been found that severe vitamin D3 deficiency can be associated with pathogenesis of 
CLBP, but this needs to be further evaluated ${ }^{8}$.

Another major factor of females observing veil, has also been found related to LBP and Vitamin D3 deficiency which needs to be further evaluated.

We conducted this study to find out the prevalence of Vitamin D3 deficiency and insufficiency in Neurosurgery OPD female patients, who complained of chronic LBP, so that it might be investigated properly and if vitamin D3 was found insufficient, should be replaced, another objective was to find the association between observing veil and vitamin D3 deficiency.

\section{METHODOLOGY}

An observational, cross-sectional study was carried out through questionnaires from 100 patients selected by stratified random sampling at Neurosurgery OPD, Civil Hospital, Hyderabad, from December, 2013 to May, 2014. Though 200 questionnaires were filled at OPD but the patients were divided into strata on the basis of locality (parts of Sindh) from which random sampling was done using the lottery method and only 100 patients were selected. Liaquat University Hospital, Hyderabad covers not only Hyderabad but also interior Sindh, making the sample nearly population representative. Sampling bias was fixed in a way that the patients were carefully chosen from different areas of the city to make the sample size nearly population representative. Vitamin D3 tests were obtained and reports were included in the data.

Only females of reproductive age i.e. 15-49 years with Idiopathic LBP were included, as our study wanted to know the relation of vitamin D3 with "Idiopathic low back pain" only. While those with known causes like fractures of spine, scoliosis / kyphosis / lordosis, Congenital spinal disorders, tumors of spinal cord/ vertebral column, degenerative spinal disorders, trauma, gynecological problems such as PID (Pelvic Inflammatory Disease) and renal diseases were excluded. These causes were ruled out by tests like Plain X-Ray lumbosacral spine, MRI Spine, abdominal ultrasound, urine DR and serum urea and creatinine levels.

Patients questionnaire were filled at OPD, followed by drawing of blood sample at Research lab for vitamin D3 test. Recall bias was fixed by multiple follow-up visits and each time the questionnaire was filled so that no missing data should remain at the end. The technology used for detecting vitamin D3 levels was ARCHITECT 25-OH Vitamin D3. This assay is a chemi-luminescent microparticle immuno assay (CMIA) for the quantitative determination of $25-\mathrm{OH}$ Vitamin D3 in serum. The amount of blood collected was 2-3cc. The results obtained were in $\mathrm{ng} / \mathrm{ml}$ (nanogram per milliliter)
The research protocol was approved by LUMHS Ethical Review Committee and informed consent was taken from all patients. Software's used were Microsoft Excel, SPSS version 16.0 and SPSS version 20.0

\section{RESULTS}

The main results are shown in Figure I out of 100 patients suffering with idiopathic LBP, 60 patients $(60 \%)$ were Vitamin D3 deficient $(0-20 \mathrm{ng} / \mathrm{ml}), 23$ patients $(23 \%)$ fell into category of Vitamin D3 insufficiency $(20-30 \mathrm{ng} / \mathrm{ml})$, whereas the percentage of patients having Vitamin D sufficiency $(30-100 \mathrm{ng} / \mathrm{ml})$ or efficiency $(>100 \mathrm{ng} / \mathrm{ml})$ was 15 patients $(15 \%)$ and 2 patients $(2 \%)$ respectively. The mean vitamin D3 level was found to be 21.8472 with a standard deviation of 17.33001 (Table I).

FIGURE I: SHOWING FREQUENCY OF VITAMIN D3 LEVELS $(n=100)$

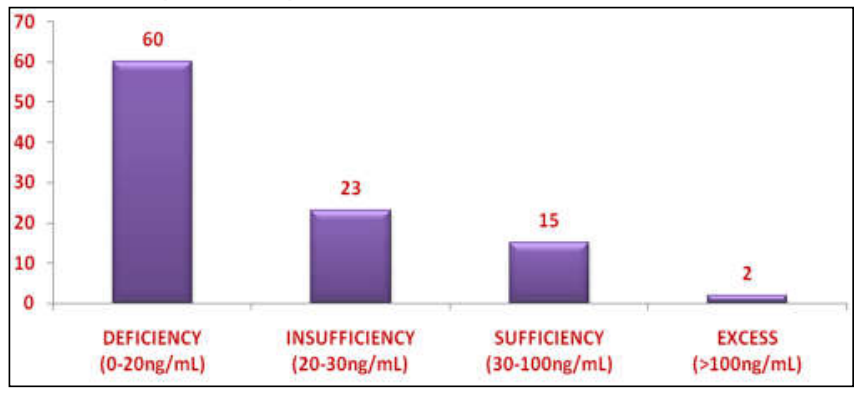

TABLE I: SHOWING MEAN AND STANDARD DEVIATION OF VITAMIN D3 LEVELS $(n=100)$

\begin{tabular}{|l|c|c|c|c|c|}
\hline & $\mathbf{N}$ & Minimum & Maximum & Mean & $\begin{array}{c}\text { Std. } \\
\text { Deviation }\end{array}$ \\
\hline $\begin{array}{l}\text { Vitamin D3 } \\
\text { levels }\end{array}$ & 100 & 3.00 & 108.90 & 21.8472 & 17.33001 \\
\hline
\end{tabular}

Another major incidental but statistically significant finding was the effect of observing veil on vitamin D3 deficiency. Out of 60 females who were vitamin D3 deficient, $49(81.7 \%)$ were often observing veil (getting no good sun exposure) and only $11(18.3 \%)$ were not at all observing veil (well-exposed to sun) Figure II.

FIGURE II: SHOWING FREQUENCY OF VITAMIN D DEFICIENCY AMONG PATIENTS OBSERVING

VEIL $(n=100)$

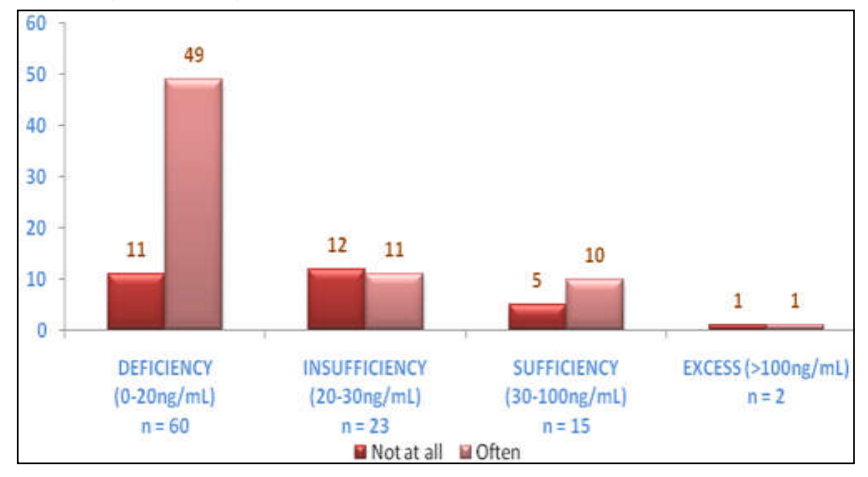


This association between observing veil and low levels of Vitamin D3 was found to be statistically significant, calculated by Pearson's Chi Square Test. ( $p$-value) Table II clearly shows a negative correlation of $-21 \%$ between observing veil and Vitamin D3 levels. It suggests that increase in veil will decrease in vitamin D3 by $21 \%$ and vice versa.

\section{TABLE II: SHOWING SIGNIFICANT CORRELATION BETWEEN VITAMIN D DEFICIENCY AND OBSERVING VEIL $(n=100)$}

\begin{tabular}{|l|l|c|c|}
\hline \multicolumn{2}{|c|}{} & $\begin{array}{c}\text { Vitamin D3 } \\
\text { Category }\end{array}$ & $\begin{array}{c}\text { Observe } \\
\text { Veil }\end{array}$ \\
\hline \multirow{3}{*}{$\begin{array}{l}\text { Vitamin D3 } \\
\text { category }\end{array}$} & Pearson Correlation & 1 & $-.214^{*}$ \\
\cline { 2 - 4 } & Sig. (2-tailed) & - & .033 \\
\cline { 2 - 4 } & $\mathrm{N}$ & 100 & 100 \\
\hline \multirow{4}{*}{ Observe veil } & $\begin{array}{l}\text { Pearson Correla- } \\
\text { tion }\end{array}$ & $-.214^{*}$ & 1 \\
\cline { 2 - 4 } & Sig. (2-tailed) & .033 & - \\
\cline { 2 - 4 } & $\mathrm{N}$ & 100 & 100 \\
\hline
\end{tabular}

*. Correlation is significant at the 0.05 level (2-tailed) Comparison of Means and Standard deviations between Vitamin $D$ deficiency and observing veil are shown in (Table III)

TABLE III:

SHOWING COMPARISON OF MEANS BETWEEN VITAMIN D3 LEVELS AND OBSERVING VEIL

\begin{tabular}{|l|c|c|c|}
\hline OBSERVE VEIL? & Mean & N & Std. Deviation \\
\hline Do not observe veil & 26.2172 & 29 & 19.30704 \\
\hline Observe veil & 20.0623 & 71 & 16.26355 \\
\hline Total & 21.8472 & 100 & 17.33001 \\
\hline
\end{tabular}

\section{DISCUSSION}

Low back pain affects many people at some point in life and in $85 \%$ of these patients, it is Idiopathic $\mathrm{LBP}^{1,2}$. Pakistan is a sunny country with adequate UV exposure, yet most of the people become Vitamin D3 deficient as they cannot afford to have a proper diet. Not surprisingly, our results also revealed similar outcomes regarding the socio-economic status of most of the Vitamin D3 deficient females, who belonged to poor families. This is consistent with a local study among adult Pakistani females which concluded that bone turnover is increased (36.8\%) along with high prevalence of Hypovitaminosis D3 $(82.8 \%)$ in otherwise healthy adult females ${ }^{9}$.

This study aimed at finding whether Vitamin D3 deficiency or insufficiency could be an associated factor towards Idiopathic LBP. The results were consistent with the hypothesis as, from 100 patients suffering with idiopathic LBP, about $60 \%$ were Vitamin D3 deficient and 23\% were Vitamin D3 insufficient. This observation is similar to a local study by Siddque SA $2011^{10}$ which reported that low levels of vitamin D3 were found in $81 \%$ of LBP patients, where cut off value of vitamin D3 was $30 \mathrm{ng} / \mathrm{ml}$. Another study showed that the severity of low back pain is directly proportional to the Vitamin D3 deficiency, and for this reason, the study recommended to evaluate LBP patients for Vitamin D3 deficiency ${ }^{11}$. Similar results were found in a study by Ghai B et al which stated that supplementation of Vitamin D3 CLBP patients can alleviate pain intensity and improve functional ability ${ }^{12}$. A meta-analysis conducted by Bansal D $2018^{13}$ also supports this hypothesis that there is high prevalence of Vitamin D3 deficiency among LBP patients. Therefore, LBP patients should be screened for Vitamin D3 deficiency and if levels of Vitamin D3 are low, it should be corrected with supplementation, which can be of curative adjunct in the treatment. Another meta-analysis conducted by Zadro $\mathrm{J}$ et $\mathrm{al}^{14}$ also concluded that LBP is associated with Vitamin D3 deficiency, in particular among younger women.

Local studies conducted in India, also concludes that severe vitamin D3 deficiency may be associated in pathogenesis of CLBP. They found that there is high prevalence of Vitamin D3 deficiency among CLBP patients in India and recommended for screening and thereby, supplementation of Vitamin D in CLBP patients ${ }^{8,15}$.

Nonetheless, a few studies also reject the alternate hypothesis and state that there is no significant association. As per Zadro JR et $\mathrm{al}^{16}$, who found that supplementation with Vitamin D3 is not more effective than placebo for the management of LBP and the results are reproducible, hence prescribing vitamin D3 supplements for LBP patients cannot be clearly recommended ${ }^{16}$. Another study by Sandoughi $M$ $2015^{17}$ also found that LBP was improved by both vitamin D3 and placebo with no statistically significant difference between the two groups.

Another major result to discuss is the relationship of observing Veil on Vitamin D3 levels and thereby, on LBP. Out of 60 patients who were Vitamin D deficient, $49(81.7 \%)$ were observing veil and only $11(18.3 \%)$ were not observing veil. This data was statistically significant. A study at Morocco supports the similar fact that veil and inadequate sunlight exposure are the dominant factors influencing Vitamin D3 deficiency ${ }^{18}$. On the contrary others say that pattern and duration of dress-up manner must not be taken as a cause for reduced levels of Vitamin $D$ before additional reasons are being judged ${ }^{19}$. The thing to ponder over is that our results revealed a significant Vitamin D3 
deficiency among females observing veil in a country that is as sunny as Pakistan and hence, this calls for attention.

Following were the strengths and limitations of the study:

Our study revealed a high prevalence of low Vitamin D3 levels among Women of Child Bearing Age with Idiopathic LBP. It confers to the fact that along with analgesics, vitamin D3 supplements and life-style modifications can be advised to such patients. This study opens a path for further investigations in this regard. To screen for Vitamin D3 deficiency and replenish it to normal levels, a major risk factor towards LBP in Women of Child Bearing Age can be mandatory to lessen a huge socio-economic and psychological burden, especially in a developing country like Pakistan which is already overburdened by many other financial issues. Primary Prevention would be more useful than Secondary and Tertiary care. This will also reduce the caseload on doctors, allowing them to work more on other emerging health problems.

Cross-Sectional study design appeared to be the major limitation of this study due to which Measurement and Design bias couldn't be fixed. Also, usually Bone Mineral Density (BMD), serum Calcium and PTH levels are tested along with Vitamin D3, but this was not possible in our setting due to limited resources and time.

\section{CONCLUSION}

Vitamin D3 deficiency or insufficiency is an associated risk factor for Idiopathic LBP, also observing veil can lead to significantly low vitamin D3 levels associated with high prevalence of LBP risk in women of child bearing age in otherwise sunny regions. Therefore, adequate vitamin D3 supplementation can be mandatory to prevent and treat LBP. This needs to be evaluated in further researches at a local level.

Ethical permission: Approval letter from Research Ethics Committee of LUMHS No. 198, Dated: 09-10-2014.

Conflict of interest: Authors of the study have no conflict of interest to declare.

Funding: There was no any funding agency.

\section{REFERENCES}

1. Meucci RD, Fassa AG, Faria NM. Prevalence of chronic low back pain: systematic review. Rev Saude Publica. 2015; 49. pii: S003489102015000100408. doi: 10.1590/S0034-8910. 2015049005874.

2. Pearce JM. A biographical study of men with chronic low back pain. Doctoral Thesis, University of Southampton, United Kingdom. 2012.

3. Patrick N, Emanski E, Knaub MA. Acute and Chronic Low Back Pain. Med Clin North Am. 2016;100(1): 169-81. doi: 10.1016/j.mcna.2015. 08.015 .

4. Bordelon P, Ghetu MV, Langan RC. Recognition and management of vitamin $D$ deficiency. Am Fam Physician. 2009;80(8):841-6.

5. Çalık $Y$, Aygün Ü. Evaluation of vitamin $D$ levels in patients with chronic low back-leg pain. Acta Orthop Traumatol Turc. 2017;51(3):243-7. doi: 10.1016/j.aott.2017. 03.006.

6. Lodh M, Goswami B, Mahajan RD, Sen D, Jajodia $\mathrm{N}$, Roy A. Assessment of Vitamin D status In Patients of Chronic Low Back Pain of Unknown Etiology. Indian J Clin Biochem. 2015; 30(2): 1749. doi: 10.1007/s12291-014-0435-3.

7. Palacios C, Gonzalez L. Is vitamin D deficiency a major global public health problem? J Steroid Biochem Mol Biol. 2014; 144 Pt A: 138-45. doi: 10.1016/ j.jsbmb.2013.11.003.

8. Panwar A, Valupadas C, Veeramalla M, Vishwas $H N$. Prevalence of vitamin D deficiency in chronic and subacute low back pain patients in India: a triple-arm controlled study. Clin Rheumatol. 2018; 37(5): 1367-74. doi: 10.1007/s10067-017-3798-z.

9. Al Faraj S, Al Mutairi K. Vitamin D deficiency and chronic low back pain in Saudi Arabia. Spine (Phila Pa 1976). 2003; 28(2): 177-9.

10. Siddique SA, Malik YM. Frequency of vitamin D deficiency in patients of low backache. Ann Pak Inst Med Sci. 2011; 7(4): 208-12.

11. Gokcek E, Kaydu A. Assessment of Relationship between Vitamin D Deficiency and Pain Severity in Patients with Low Back Pain: A Retrospective, Observational Study. Anesth Essays Res. 2018;12(3): 680-84. doi: 10.4103/aer.AER_96_18. Erratum: Assessment of Relationship between Vitamin D Deficiency and Pain Severity in Patients with Low Back Pain: A Retrospective, Observational Study. [Anesth Essays Res. 2018]. Available from:https://www.ncbi.nlm.nih.gov/ pubmed/ 30662139.

12. Ghai B, Bansal D, Kanukula R, Gudala K, Sachdeva N, Dhatt SS, et al. Vitamin D Supplementation in Patients with Chronic Low Back Pain: An Open Label, Single Arm Clinical Trial. Pain Physician. 2017; 20(1): E99-E105.

13. Bansal D, Boya CS, Vatte R, Ghai B. High Prevalence of Hypovitaminosis D in Patients with Low Back Pain: Evidence from Meta-Analysis. Pain Physician. 2018;21(4):E389-E399.

14. Zadro J, Shirley D, Ferreira M, Carvalho-Silva AP, Lamb SE, Cooper $\mathrm{C}$, et al. Mapping the Association between Vitamin D and Low Back 
Pain: A Systematic Review and Meta-Analysis of Observational Studies. Pain Physician. 2017; 20 (7): 611-40.

15. Ghai B, Bansal D, Kapil G, Kanukula R, Lavudiya $S$, Sachdeva N. High Prevalence of Hypovitaminosis D in Indian Chronic Low Back Patients. Pain Physician. 2015; 18(5): E853-62.

16. Zadro JR, Shirley D, Ferreira M, Carvalho Silva AP, Lamb SE, Cooper C, et al. Is Vitamin D Supplementation Effective for Low Back Pain? A Systematic Review and Meta-Analysis. Pain Physician. 2018; 21(2): 121-45.

17. Sandoughi M, Zakeri Z, Mirhosainee Z, Mohammadi M, Shahbakhsh S. The effect of vitamin $D$ on nonspecific low back pain. Int $\mathrm{J}$ Rheum Dis. 2015;18(8):854-8. doi: 10.1111/1756185X.12172.

18. Allali F, El Aichaoui S, Khazani H, Benyahia B, Saoud B, El Kabbaj S, et al. High prevalence of hypovitaminosis D in Morocco: relationship to lifestyle, physical performance, bone markers, and bone mineral density. Semin Arthritis Rheum. 2009;38(6):444-51. doi: 10.1016/j.semarthrit.2008. 01.009 .

19. Al Attia HM, Ibrahim MA. The high prevalence of vitamin $D$ inadequacy and dress style of women in the sunny UAE. Arch Osteoporos. 2012; 7: 307-10.

AUTHOR AFFILIATION:

Dr. Mahjabeen Memon (Corresponding Author)

Resident, Department of Neurosurgery

Liaquat University of Medical \& Health Sciences

(LUMHS), Jamshoro, Sindh-Pakistan.

Email: mahjabeen151@hotmail.com

\section{Dr. Vashdev Khemani}

Assistant Professor

Department of Neurosurgery

LUMHS, Jamshoro, Sindh-Pakistan.

Prof. Riaz Ahmed Raja

Professor, Department of Neurosurgery

LUMHS, Jamshoro, Sindh-Pakistan. 